\title{
DIVERSIDADE HIDROGEOMORFOLÓGICA DE NASCENTES NOS DOMÍNIOS DOS MARES DE MORROS: CASOS DO JARDIM BOTÂNICO DA UFJF (JUIZ DE FORA - MG)
}

\author{
Luiz Otávio Marques $^{(\mathrm{a})}$, Miguel Fernandes Felippe ${ }^{(\mathrm{b})}$ \\ (a) Curso de Geografia, Universidade Federal de Juiz de Fora, lotams@ive.com \\ (b) Departamento de Geociências, Universidade Federal de Juiz de Fora, miguel.felippe@ufjf.edu.br
}

\section{Eixo: GEODIVERSIDADE, GEOARQUEOLOGIA E PATRIMÔNIO NATURAL}

\begin{abstract}
Resumo:
As nascentes são sistemas ambientais muito heterogêneos, sendo constituídas pelo engendramento de vários elementos. Sua estrutura é condicionada tanto pelas características ambientais regionais, quanto pelas locais, com ênfase no contexto geológico-geomorfológico. Porém, as pesquisas científicas sobre as nascentes ainda são escassas, sobretudo no âmbito da geografia. Nesse ínterim, o presente trabalho tem como objetivo discutir as características fisiográficas e os elementos estruturantes das nascentes encontradas no Jardim Botânico da Universidade Federal de Juiz de Fora, Minas Gerais. Ao todo, foram encontradas 14 nascentes com características distintas e inseridas em diferentes condições ambientais, confirmando a diversidade das nascentes.
\end{abstract}

Palavras chave: Nascentes, Geodiversidade, Juiz de Fora - MG.

\section{Introdução}

Desde a Conferência de Estocolmo, em 1972, devido à degradação ambiental e a extinção de espécies, tem se falado cada vez mais sobre a perda da biodiversidade (SANCHEZ, 2015), o que se tornou um dos principais assuntos da problemática ambiental. Porém, a lógica capitalista de exploração dos recursos naturais, também ocasiona uma significativa perda da geodiversidade, que, de acordo com Brilha (2005, p. 17), não recebe o mesmo grau de reconhecimento em comparação a biodiversidade.

De acordo com Gray (2008, p. 287), o termo "geodiversidade" é relativamente novo, tendo sido utilizado pela primeira vez em 1993, na Conferência de Malvern que ocorreu no Reino Unido. Nesse ocasião, o termo foi empregado na gestão de áreas de proteção ambiental, tendo surgido da necessidade de se criar um termo análogo ao de biodiversidade, que se referisse a todos os elementos abióticos do meio natural (SERRANO e RUIZ FLAÑO, 2007). Entretanto, deve-se ressaltar que o termo não foi aceito de imediato pela comunidade científica internacional, fazendo com que alguns trabalhos publicados anteriormente utilizassem termos análogos (GRAY, 2004). 
Contudo, a abordagem de conceitos como o de geodiversidade dentro das ciências ambientais sempre esbarrou em deficiências teórico-epistemológicas que limitavam a capacidade de compreensão das relações entre os complexos elementos envolvidos. Com isso, a Geoecologia das Paisagens, que surgiu da necessidade de se incorporar os fundamentos da Ecologia das Paisagens e Gestão Ambiental e Territorial, com maior ênfase na dimensão espacial dos fenômenos, através da incorporação do conceito de paisagem (RODRIGUES et al., 2004), ganha importância.

Dentre os elementos pouco explorados academicamente sob a lente da geodiversidade, está a nascente. Reconhecidamente multifacetada e com características fisiográficas definidas de modo multiescalar (DAVIS, 1996; VALENTE e GOMES, 2005; FELIPPE e MAGALHÃES JR., 2014), as nascentes tendem a ser consideradas erroneamente de modo simplista, não se observando sua geodiversidade.

Inserindo-se nessa lacuna, o objetivo deste trabalho é discutir a variabilidade dos elementos hidrogeomorfológicos, incluindo aqueles da geodiversidade, que caracterizam as nascentes de cursos d' água do Jardim Botânico da Universidade Federal de Juiz de Fora, Minas Gerais.

O município de Juiz de Fora, em Minas Gerais, está inserido no Domínio Morfoclimático dos Mares de Morros, o qual "corresponde a área de mais profunda decomposição das rochas e de máxima presença de mamelonização topográfica em caráter regional de todo o país” (AB' SÁBER, 2005). Especificamente, o Jardim Botânico da Universidade de Juiz de Fora (JB-UFJF) se constitui em uma área verde, integrada à um dosprincipais remanescentes de Mata Atlântica do município, a chamada Mata do Krambeck, no passado, uma antiga fazenda de cultivo do café (BRITO, 2013).

A área do JB-UFJF está assentada sobre uma sequência de rochas metassedimentares de idade neoproterozóica que constituem a Megassequência Andrelândia (TUPINAMBÁ et al., 2007). E o clima da área pode ser classificado como Cwa - um clima mesotérmico com verões quentes e chuvosos (CESAMA, 2010).

\section{Metodologia}

Inicialmente, com o intuito de localizar todas as nascentes da área de estudo, foram realizadas campanhas de campo iniciadas na foz da bacia, na qual o Jardim Botânico está inserido. Seguindo a rede de drenagem, de jusante para montante, pôde-se visualizar as confluências e encontrar todas as nascentes. Ao todo foram mapeadas 14 nascentes, com o auxílio de um receptor GPS modelo Garmin GPSMAP 76CSx. Em um segundo momento, novas campanhas de campo foram feitas para a obtenção de informações fisiográficas das nascentes. Foi elaborado e aplicado um check-list contendo informações básicas das nascentes e também de algumas características ambientais de seu entorno. 
A vazão das nascentes foi mensurada a partir da coleta de um volume aleatório de água em sacos plásticos. O tempo de coleta foi obtido em cronômetros digitais e o volume coletado, aferido em seringas com intervalo de leitura de $1 \mathrm{~mL}$. Os procediementos foram realizados em triplicata. Além da vazão, a profundidade das coberturas superficiais também foi mensurada com auxílio de trena, a 1metro de distância do ponto/área de exfiltração nas margens direita e esquerda e a montante do mesmo. Esses procedimentos foram baseados no trabalho de Felippe e Magalhães $\operatorname{Jr}$ (2014).

Em gabinete, para concluir o mapeamento, os pontos coletados em campo foram plotados no software ArcGIS 10.2.2, sobrepostos a uma fotografia aérea (escala: 1/2000) da Prefeitura Municipal de Juiz de Fora, do ano de 2007. Os dados primários foram trabalhos no software Excel 2013 e, em seguida, com base no mapeamento e principalmente, na análise das informações contidas nos check-lits de cada nascente, pode-se discutir sobre a geodiversidade das nascentes sob a luz da literatura cientifíca existente sobre o assunto.

\section{Resultados e Discussão}

Ao se considerar as nascentes como sistema ambiental (FELIPPE e MAGALHÃES JR., 2013), deve-se compreender o substrato (solo, rochas e também as feições geomorfológicas) onde ocorrem a exfiltração da água subterrânea. Assim, a geodiversidade de um conjunto de nascentes é abordada, neste trabalho, pela variabilidade de suas características estruturais.

Metade das nascentes do JB-UFJF (Figura 1) se encontram localizadas nas encostas cobertas por matas secundárias, em áreas onde predominam uma vegetação sublenhosa. As nascentes Jbn12, Jbn19 e Jbn1 possuem uma vegetação de caráter mais lenhoso, mas deve-se ressaltar que as duas primeiras estão envoltas por grandes miotas de bambus. As nascentes Jbn6, Jbn14 e Jbn9, situadas nas proximidades do lago principal estão sob uma vegetação herbáceo-graminosa. Assim, este último grupo de nascentes tem menor proteção da vegetação e estão mais vulneráveis às intervenções antrópicas que ocorrem no local.

Devido ao predomínio de áreas com uma vegetação sublenhosa, no JB-UFJF, a maioria das nascentes estão sob dósseis árboreos semiabertos ou abertos.

Em relação a localização das nascentes nos compartimentos das vertentes, mais da metade delas estão na baixa vertente. Outras três (Jbn10, Jbn12 e Jbn13) se situam na porção média das vertentes em que se encontram. Somente duas nascentes estão localizadas na calha de seus respectivos canais fluviais.

No tipo de material encontrado nas nascentes, foi possível constatar uma clara predominância de material coluvial, eluvial e cóluvio - eluvial.

Nos aspectos hidrogeomorfológicos, pode se notar um claro predomínio de nascentes com as mesmas características morfológicas. Dentro do conjunto de nascentes englobadas neste trabalho, a morfologia 


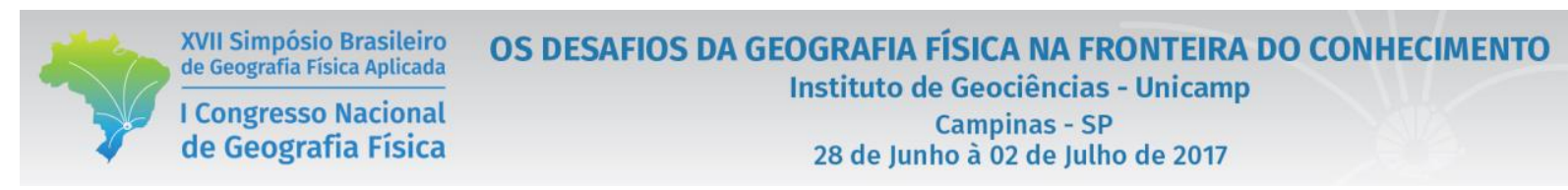

mais comum de se encontrada no JB-UFJF é a concavidade, abarcando sete nascentes. Segundo Lucena et al. (2012), as nascentes em concavidade ocorrem em trechos côncavos da vertente e formam canais apenas à jusante da exfiltração. Nas campanhas de campo, também foram encontradas três nascentes em duto horizontal, cuja exfiltração ocorre em canais erosivos subterrâneos horizontais que interceptam a superfície em algum ponto da vertente (SILVA, 2015). As demais nascentes têm as suas exfiltraçõoes condicionadas pela presença de afloramentos rochosos ou no talvegue do canal. Sobre o tipo de exfiltração das nascentes do JB-UFJF, foram encontradas seis nascentes difusas, onde a água exfiltra em uma área dispersa; quatro nascentes pontuais e outras três nascentes múltiplas.



Figura 1: Localização das nascentes do Jardim Botânico da UFJF.

\section{Considerações Finais}

No Jardim Botânico da Universidade Federal de Juiz de Fora, pode-se perceber uma certa regularidade das características das nascentes, predominando morfologia em concavidade e exfiltração difusa. Todavia, mesmo nessa pequena área, algumas nascentes específicas são distintas, necessitando estudos verticalizados para explica-las. O conhecimento acerca das nascentes e dos elementos que as constituem se faz necessário para que medidas mais eficazes sem adotadas na gestão do Jardim Botânico.

\section{Agradecimentos}

À Pró-Reitoria de Pós-Graduação e Pesquisa da Universidade Federal de Juiz de Fora pela concessão da bolsa de iniciação científica. À diretoria do Jardim Botânico da UFJF pelo apoio logístico. Ao discente Ataniel Moreira Alves pelo apoio na fase inicial da pesquisa. 


\section{REFERÊNCIAS}

28 de Junho à 02 de Julho de 2017

AB' SÁBER, A. Os Domínios da Natureza do Brasil: Potencialidades paisagísticas. São Paulo: Ateliê Editorial, 2005.

BRILHA, J. Património Geológico e Geoconservação: A Conservação da Natureza na sua Vertente Geológica. Braga: Palimage Editores, 2005.

BRITO, P. S. A Comunidade Arbórea de um trecho de Floresta Atlântica Secundária no Jardim Botânico da Universidade Federal de Juiz de Fora. Dissertação (mestrado). Universidade Federal de Juiz de Fora, 2013.

BRITO, P. S.; CARVALHO, F. A. Estrutura e diversidade arbórea da Floresta Estacional Semidecidual secundária no Jardim Botânico da Universidade Federal de Juiz de Fora. Rodriguésia, Rio de Janeiro, v. 65, n. 4, p. 817-830, 2014.

CESAMA. Hidrografia em Juiz de Fora. Disponível em: < http://www.cesama.com.br/?pagina=hidrografia > Acesso em: 10 de fev. 2017.

DAVIS, S. N. Hydrogeology. New York: 1966.

FELIPPE, M. F.; MAGALHÃES JR, A. P. Conflitos conceituais sobre nascentes de cursos d' água e propostas de especialistas. Geografias, Belo Horizonte, v. 9, n. 1, p. 70-81, 2013.

SILVA, E. C. Caracterização de Nascentes da Sub-bacia do Rio Barrocas, Município de Senhor do Bonfim, Bahia. Dissertação (mestrado). Universidade Federal da Bahia, 2015.

FELIPPE, Miguel. F.; MAGALHAES JR., A. P. Desenvolvimento de uma tipologia hidrogeomorfológica de nascentes baseada em estatística nebulosa multivariada. Revista Brasileira de Geomorfologia, v. 15, p. 393-409, 2014.

GRAY, M. Geodiversity: developing the paradigm. Association Proceedings of the Geologists, p. 287-289, 2008.

GRAY, M. Geodiversity: valuing and conserving abiotic nature. S.1.: John Wiley \& Sons Ltd., 2004.

LUCENA, U.; CARMO, L.; MARQUES, C.; FELIPPE, M. F. Classificação de nascentes da Reserva Ecológica do Clube Veredas: colaboração para o manejo das reservas particulares de Belo Horizonte, MG. Simpósio Nacional de Geomorfologia. IX. Resumos....Rio de Janeiro, 2012.

RODRIGUEZ, J. M. M.; SILVA, E. V. da; CAVALCANTI, A. P. B. Geoecologia das Paisagens: uma visão geossistêmica da análise ambiental. Fortaleza: Editora UFC, 2004.

SÁNCHEZ, L. E. Avaliação de impacto ambiental. Oficina de Textos, 2015.

SERRANO, C.; RUIZ FLAÑO, P. Geodiversidad: Concepto, Evaluación y Aplicación Territorial el Caso de Tiermes Caracena (Soria). Boletin de la A. G. E., n. 45, p. 79-98, 2007.

TUPINAMBÁ, M.; HEILBRON, M.; DUARTE, B. P.; NOGUEIRA, J. R.; VALLADARES, C.; ALMEIDA, J.; SILVA, L. G. E.; MEDEIROS, S. R.; ALMEIDA, C. G.; MIRANDA, A.; RAGATKY, C. D.; MENDES, J.; LUDKA, I. Geologia da Faixa Ribeira Setentrional: estado da arte e conexões com a Faixa Araçuaí. Geonomos, v. 15, p. 67-79, 2007. 


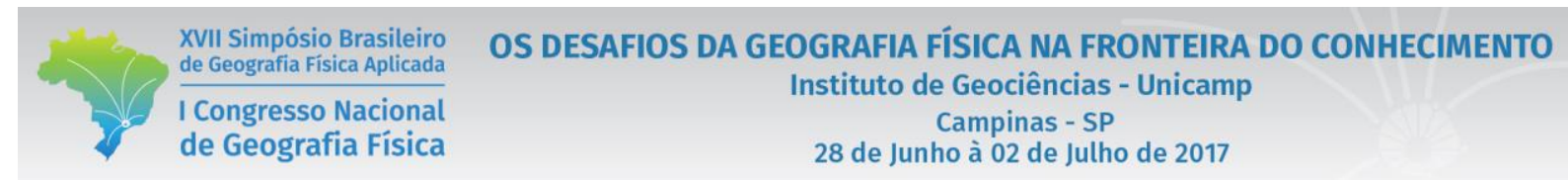

VALENTE, O. F.; GOMES, M. A. Conservação de nascentes: hidrologia e manejo de bacias hidrográficas de cabeceiras. Viçosa: Aprenda Fácil, 2005. 